\title{
ENVIRONMENT
}

\section{MANAGING ENVIRONMENTAL UNCERTAINTY}

Henry T. Epp

2 Candle Terrace SW, Calgary, AB, T2W 6G7; E-mail: <htepp@shaw.ca>

\section{Introduction}

Environmental management is a rapidly advancing application of science, especially ecology. In recent years, the science of uncertainty has begun to have important implications for environmental management practices, especially in a place with as much development and as many ecological tension zones as there are in western Canada. A read of recent literature on the potential effects of an expanding human population and technology on global climate is enough to convince even the most sceptical that uncertainty is very real in nature, and that it is of concern to individuals and administrations everywhere.

What are some of the environmental uncertainties in Canada's prairie provinces, viz. Manitoba, Saskatchewan, and Alberta? First, the amount of annual precipitation in the southern half of these provinces is less than in other parts of Canada, and it is also less certain. ${ }^{1}$ Droughts and floods occur at unpredictable intervals. Next, ecotones between major ecosystems are places of even more uncertainty due to potential boundary relocation. Human activity also is a great contributor to uncertainty as development proceeds northward and changes continually in already developed areas. Finally, the spectre of long-term climate change causes further uncertainty within already existing uncertainties. ${ }^{2}$

In this paper, I address the nature of uncertainty in the environment, apply this to Canada's prairie provinces, and suggest ways in which society can continue to use resources and adapt itself to inherently uncertain ecological processes without destroying them.

\section{Role of Uncertainty in Nature}

The noted ecologist and historian of ecology Frank Benjamin Golley ${ }^{3}$ agrees with Daniel Simberloff ${ }^{4}$ that "ecological systems are stochastic and indeterminate... and that the history of science is a dialectical opposition between determinism and indeterminism." This comment represents a change in life view assumptions that has affected science in the latter years of the twentieth century, namely, the recognition of uncertainty as an important constituent of natural processes, and the search for the role of uncertainty in these processes. The new approach has added to the search for regularities or certainties in nature fitting into the assumption that we could eventually know everything about nature and then be able to predict events with accuracy, and even control them to our human benefit. ${ }^{5}$ This old assumption fits neatly with the also old belief that nature consists of natural resources, which exist primarily for our human benefit, and all that we have to do is to find them and exploit them. ${ }^{6,7}$ Now we know better, and we are beginning to shed some of our past hubris regarding nature, our view of which has led us to make it less predictable even while we have been trying to increase resource predictability. 


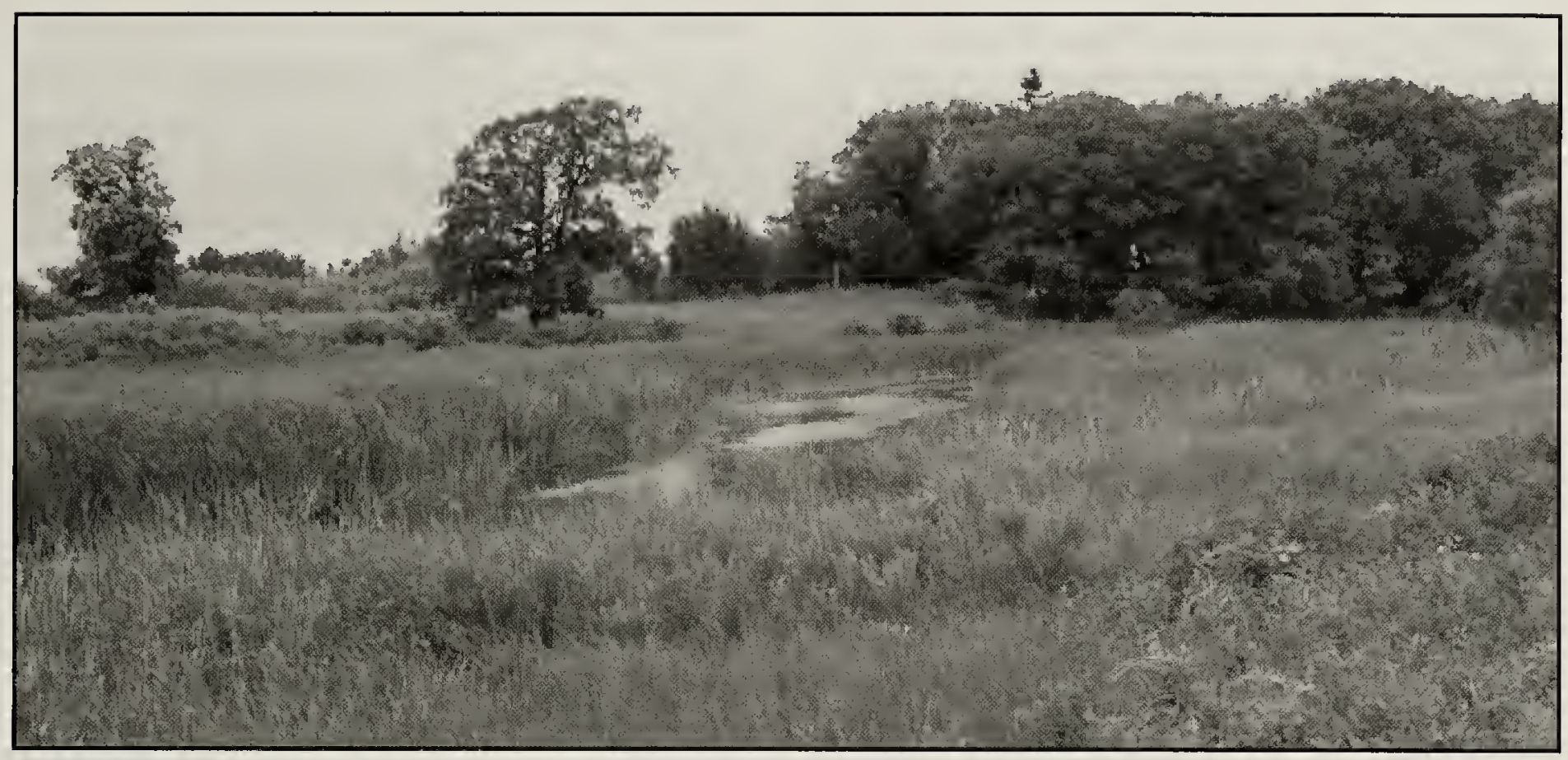

Eastern parkland, Cook's Creek, southeastern Manitoba.

Henry Epp

The acknowledgment and study of uncertainty in nature did not arise suddenly, but grew gradually as the twentieth century progressed. The ecosystem concept in ecology helped steer the thoughts of biologists to the need to incorporate uncertainty into explanations and predictions, as it became necessary to factor in the intuitively unpredictable weather and climate influences. ${ }^{3,8,9}$ Older ecosystem models focused on ecological succession and thermodynamics, the ultimate state being energy equilibrium, a continual recycling of energy. Newer models incorporate the role of uncertainty in process operations. ${ }^{7}$

A brief definition of the ecosystem concept is in order. The comprehensive definition by Higashi and Burns ${ }^{10}$ incorporates Odum's ${ }^{8}$ older definition: an "ecosystem is a physical entity: a dynamical system consisting of a biological entity, typically a regional biota (community), together with the environment." This definition requires further definition of what a system is and, especially, what a dynamical system is. Simply put, a system is a set of relationships among objects and their attributes within their environment. ${ }^{11} \mathrm{~A}$ system, then, is a discrete and active entity in which complex actions take place, an entity that is more than the sum of its parts, a synergism. A dynamical system is one in which no system state is ever exactly like the one preceding it, meaning that it is subject to continual and permanent change. The identification of permanent change as inherent in an ecosystem leads logically to identifying the role of uncertainty in ecosystems. Ecosystems tend not to behave dynamically most of the time. Usually, an ecosystem behaves as an adaptive system, which adjusts or adapts its functions to return to normal near equilibrium following minor disturbance. Dynamical, non-repetitive changes usually do not occur until the noreturn process threshold in disturbance tolerance is exceeded in any specific instance. This ecosystem trait makes identification of tolerance thresholds very important in ecosystem management.

The uncertainty in ecosystems is rooted in the uncertainty inherent in all physical and chemical systems. Uncertainty was of no small concern to physics during the first half of the twentieth century as physicists struggled to cope with quantum theory. ${ }^{12}$ During the 1960 s, the study of 
uncertainty received a huge boost by the discovery of rules of unpredictability in climate by Edward Lorenz, ${ }^{13}$ which later became the basis for chaos-complexity theory.$^{14}$ After a brief time in the media limelight, chaos theory settled back into being part of a more comprehensive selforganization theory. ${ }^{15}$

How do systems subject to selforganization influences actually work? Complex systems have parameters, a condition in our universe which is not yet at entropy, the ultimate random equilibrium predicted by the second law of thermodynamics. ${ }^{12}$ "Parameters are functions of the distribution generating the data, ${ }^{16}$ causing non-random clumping of information in a system not at entropy. The answer lies in the strange form of certainty that is always present in uncertainty. No system falls from organization into total disarray. Rather, there is always an ordered process leading to disorder, at which time potentially new system orders appear in profusion, and then there is an orderly return to order. Only one or a few of these potentials can survive after the others are out-competed, and then it arises from the mess as a new system order, self-organization. The new order, however, is never entirely predictable from the state of the old order.

Ecosystems are subject to the rules of self-organization as are other systems, and the lesson to environmental management here is twofold: (1) the change process is evolutionary, due to a natural, undirected, selection from possibilities, so that once a selection has occurred, there is no turning back; (2) maintenance of order in an ecosystem is underlain by the disorder that always lies in the background, causing variation, providing uncertainty a very important role in ecosystem maintenance as it generates new system orders from which selection from among new possibilities then proceeds in an environment that restricts possibilities due to parameters or boundaries. Hence, ecosystems are non-linear systems, seldom in complete equilibrium. ${ }^{7,17}$

Non-linear systems are never quite balanced. This fact may surprise those who are used to thinking of a wilderness

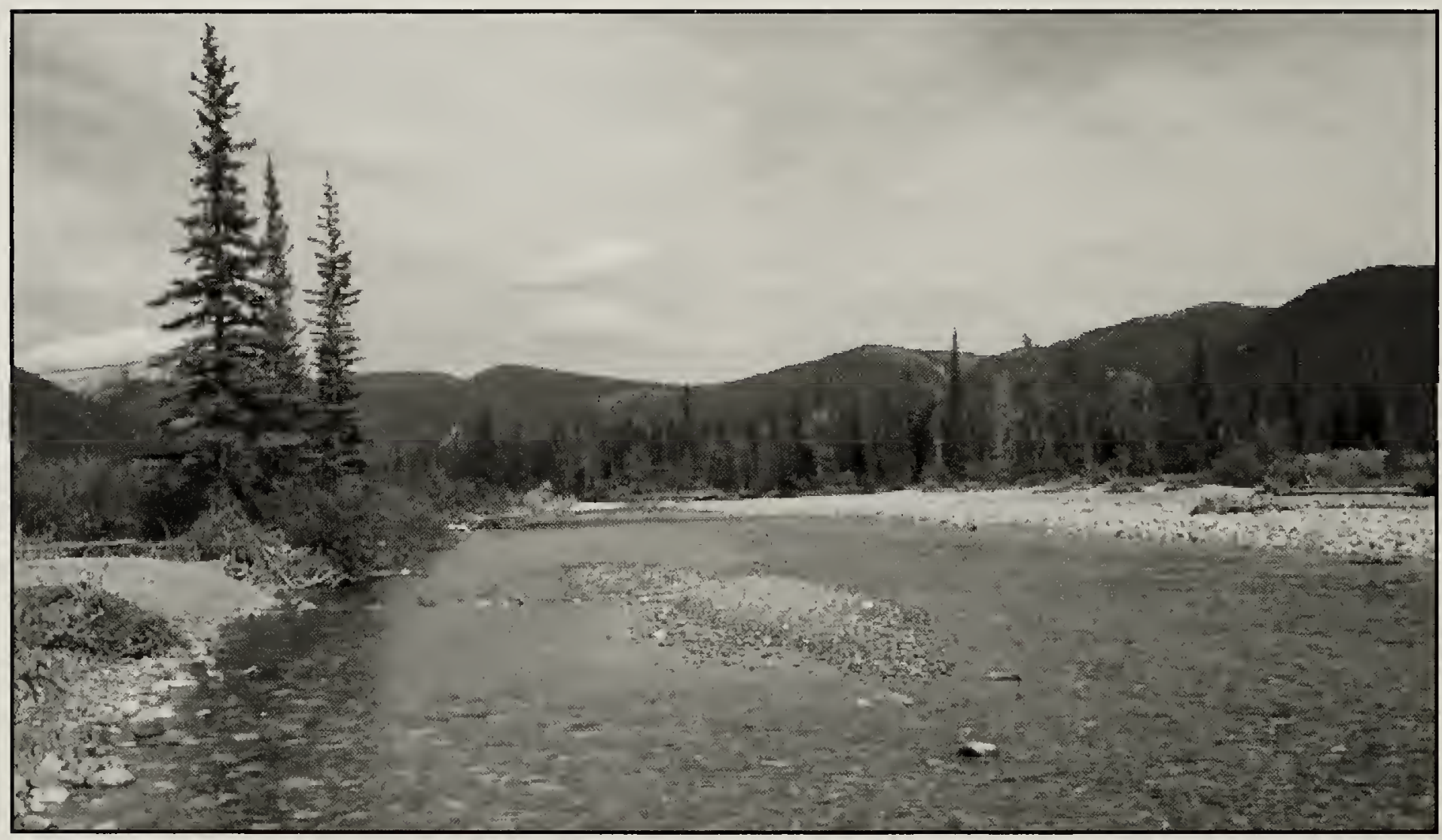

Foothills, Elbow River, southwestern Alberta.

Henry Epp 
environment as being in balance (the "balance of nature"). Balance or equilibrium does occur, but it is always unstable and subject to disequilibrium upon disturbance. Permanent change or evolution would not occur at all or proceed exceedingly slowly in a permanently balanced ecosystem. The well known evolutionary speed race between the cheetah and the gazelle, for example, would cease if the balance between the two species was stable over a long period of time.

Having established that uncertainty is ubiquitous in nature, and that it contributes to variation in ecosystems by enabling potentially new system orders, an important function of uncertainty in an ecosystem, then, is to improve the certainty of recovery given serious disruption. This sounds contradictory, that uncertainty underlies certainty, but the concept is central to self-organization.

\section{Environmental Management Implications}

Aprominent environmental management assumption holds that it is important to maintain ecosystem processes, thereby maintaining ecological integrity. ${ }^{17-19}$ Yet, conserving processes is not the same as maintaining an ecological status quo. Ecosystem change is normal and natural and to be expected, but unusually severe disturbance can push processes over the edge of recovery and trigger a chaotic interval, following which there may be re-establishment of order, but the new order will not be predictable. Processes have thresholds of tolerance of disturbance, and identifying these is useful to ecosystem management. An example of where a process threshold is important is a place where ungulate populations are regulated by predators, as is the case in the Ngorongoro crater in Tanzania, where several predator species prey on ungulates. ${ }^{20}$ The predators include lions, spotted hyenas, leopards, cheetahs, and wild dogs. Removing one predatory species would be unlikely to cause huge increases in prey populations, but removing them all certainly would do so. Obviously, removing predator species one by one eventually would result in exceeding a tipping point or threshold, and prey population regulation would cease. North American equivalents to Ngorongoro involving a suite of large mammalian predators no longer exist, due to massive human interference with predator-prey relationships.

Not all ecological processes include regulatory or balancing actions. An example of an ecosystem in which ungulate populations are not regulated by predators is one in which annual migration events occur. ${ }^{20}$ The SerengetiMara ecosystem in Kenya and Tanzania is one such case, another is the tundrataiga ecosystem in northern Canada with its migratory caribou populations, and a third is the former North American plains ecosystem with its migrant bison herds. ${ }^{20-22}$ In all of these ecosystems, ungulates are or were not regulated by predators, but by food supply or other influences. ${ }^{20}$

Why do migratory prey populations tend to elude regulation by predators? The answer is simple enough, explained thoroughly by Fryxell et al. ${ }^{20}$ Migrant ungulates are either non-territorial or only partially so, but most predators are territorial, with individuals capable of only very limited travel beyond defended territories. This means that at least once a year, for months on end, most predators are limited to resident prey. These residents tend to be either territorial, dispersed over their terrain, not clumped, or resident populations of non-territorial species; while the latter do exist, they are unlikely to comprise more than $10 \%$ of the total population of a species in 
a defined ecosystem. ${ }^{20}$ Hence, most predator populations are limited to those that are able to survive on resident prey, leaving the migrant prey to swarm outside of regulation by predation. This information is very important to game managers, as migrant populations are capable of sustaining a much higher human harvest rate than are residents. A difficulty with management, however, is that prey populations that are not regulated by predators are subject to greater unpredictable fluctuations in numbers than are regulated populations, so that human harvest can never be consistent over long time stretches. Migratory caribou are notoriously subject to such population fluctuations. ${ }^{23}$

The biological literature links uninterrupted functioning of ecological processes with maintenance of biodiversity. ${ }^{24,25}$ Hence, the environmental management literature is full of the virtues of biodiversity. Managers frequently actively seek out for protection those parts of ecosystems with the greatest biological variability. Why? The answer lies in that those parts of ecosystems with the highest levels of variability often are the least severely affected by outside disturbances, including human activities. Ecological processes and ecosystems with high levels of variability tend to be more resilient to outside disturbance than are those with low levels of variability. ${ }^{24,26}$ However, recent research in Switzerland indicates that this is not a rule that applies to all ecological processes equally, specifically plant growth reaction to drought. ${ }^{27}$ Contrary to expectations, "species-poor systems" may be more resilient to drought than are "species-rich systems." Yet, even more recent research in aquatic ecosystems has shown that habitat or spatial heterogeneity and "disturbance regimes" are important ecological characteristics that contribute to system resilience. ${ }^{28}$ This situation holds true especially in ecosystems with predator-prey processes, which were not included in the Swiss research.

Clearly, ecological diversity contributes to resilience to disturbance, even if predictability of such resilience is less than $100 \%$. Complicating matters, disturbance also contributes to the very diversity which provides resilience to it. ${ }^{29}$ Recognizing such interconnectivity of processes is important to environmental managers striving to maintain ecosystem processes.

Also important to environmental management is the fact that ecosystems normally operate as adaptive systems as defined by Harvey, ${ }^{11}$ not as dynamical systems, returning to more or less the original state of operation following recovery from minor disturbances. Recovery from disturbance is an old ecological theme, involving succession and energy transfers. ${ }^{7}$ Ecological process thresholds are important here; if a threshold is exceeded by a disturbance, dynamical activity may ensue, with uncertainty ruling. ${ }^{30}$ The only certainty then is that a new system order will eventually re-establish itself, but its nature will be unpredictable. No environmental management organization desires to cope with the unpredictability of an ecosystem gone dynamical. A diverse ecosystem has more potential system process pathways upon which natural selection acts once process thresholds are exceeded, than does a monoculture ecosystem, for example. Ecological collapse of monocultures is an ever present agricultural management problem, ${ }^{31}$ an event much less likely to occur in varied ecosystems. Hence the management emphasis tends to be on maintaining biodiversity.

Interestingly, it is not ecological equilibrium that generates the biodiversity 
needed to maintain that very equilibrium, but disturbance and heterogeneity. A management implication is almost counterintuitive, that ecosystems should not be protected from all disturbances. Uncertainty science teaches us that if the equilibrium-disturbance threshold is exceeded, the ecosystem will enter a chaotic interval which severely reduces predictability of outcome. The answer is to maintain some disturbance but not so much that it exceeds process thresholds. Human disturbances should emulate natural ones, which tend to be sporadic, not continual, usually not exceeding tolerance thresholds. Resilience lies partly in the uncertainty of natural disturbances, and less so in the certainty of either continuous human disturbance or protection from outside influences. Research to establish process thresholds is therefore essential.

How can we maintain biodiversity in the face of increasing development pressures? A common approach is to seek out for protection the most diverse areas, i.e., ecosystems 'hot spots. ${ }^{32}$ These need to be protected from intensive development, allowing some human activities in the least diverse areas. The population of any particular species within an ecosystem is not distributed uniformly over its habitat. Ecologists identify 'source' and 'sink' habitats. ${ }^{33,34}$ A source habitat is the area in which the ecological niche of the species is at its best, enabling potential population gain. A sink habitat is an area occupied by a species, but in which the ecological niche is poor enough so that there is overall loss in numbers. This means that specific populations in sink areas are maintained only when there is overflow from source areas.

Source and sink effects create a difficulty for the environmental manager. The most biologically diverse areas frequently are ecotones, the zones of overlap between major ecosystems or ecozones. In the prairie provinces, the most important ecotone is the aspen parkland, the border zone between the prairie grasslands to the south and the boreal forest to the north. ${ }^{35,36}$ Both boreal forest and prairie species spill over into this ecotone from their respective ecozones. This creates an edge effect, a zone of high species diversity. ${ }^{8,33,37}$ While ecological edges are places of high biodiversity, this fact can create a false confidence in promoting such places for preservation in lieu of protecting less diverse source areas. Not all, even carefully researched, environmental management recommendations and plans recognize this management conundrum. While complex ecosystems tend to be more resilient to disturbance than simpler ones, it is more hubris than ecological science to promote edge areas for protection to the exclusion of core source environments. Protecting sink habitats alone hints at a false confidence in maintaining biodiversity. In any edge area, a slight climatic change will favour one ecosystem over the other, worsening the source effect for the species of the receding ecosystem, an uncertainty that is certain. Yet it is also important to protect the areas of uncertainty because the secret of sound ecosystem management is not to maintain stability or balance, but to maintain resilience. Resilience relies on the presence of variation, which itself is supported by the presence of uncertainty. Hence, while biodiversity is an overall guide to what needs protection, maintaining ecological process stability requires a judicious choice of diverse areas in both source habitats and ecotones. Moreover, equally important to attain this end is a variable protection plan, one that continually identifies sensitive and resilient areas as they change with climatic variance and human disturbance. The plan then moves to protect the 
parts of ecosystems required for overall process maintenance, which is underlain by resilience. Clearly, some sites should be protected permanently, but large areas change quickly enough that different parts may need to be protected at different times. Environmental management needs to adjust its methods to ecosystem process changes in any particular place under such management. Holling has called this "adaptive management". ${ }^{38}$

\section{Loci of Uncertainty in Prairie Environments}

Environmental uncertainties can be classified according to whether they are natural or anthropogenic (human-caused) in origin. Environmental uncertainty has three major effects on ecosystems: (1) increased genetic and process variation, enhancing resilience to disturbance, (2) instances of disequilibrium, such as population swarms, and sudden population losses in some species, and (3) zonal boundary shifts due to climate change. While all of these effects can be considered neutral in a natural ecosystem, humans alter ecosystems to ensure certainty of resources for themselves. Human-caused uncertainties can influence all three effects, so that excessive resource use is likely to push uncertainties over their resilience thresholds and cause further, often uncontrollable, uncertainties. This has already happened in the prairie grasslands ecosystem, where cultivation and overgrazing exceeded the process thresholds long ago. The dominant agricultural ecosystem that has replaced the natural one has become fairly stable as technology has improved, but its resilience remains very shaky and is easily upset by droughts, pest swarms, loss of genetic variability, and continued nutrient depletion. ${ }^{39}$ Actions to increase the certainty of economic gains have created new uncertainties that scientists have not altogether learned how to cope with, at least not when climatic uncertainties increase. The story of the destruction of the original grasslands ecosystem in western Canada and its agricultural replacement is well known, ${ }^{19}$ and will not be discussed here.

The aspen parkland ecotone has fared no better than the grasslands with regard to agricultural development, ${ }^{35}$ except that aspen stands remain fairly abundant over most of the range. The boreal forest to the north has not yet fared as badly as the grasslands and parklands, but clearcutting remains an important economic pursuit. The saving grace to date has been regulation by governments to restrict the size and shape of clearcuts, so that at least a rough simulation of natural fire disruption has been attained, although not everywhere..$^{40}$

During the last years of the twentieth century and the first few years of the twenty-first century, an ecologically disruptive force that has received the most public attention has been the potential of climate change, viz. global warming caused by anthropogenic release of greenhouse gases. The most important source of information on global warming available at this time is the Intergovernmental Panel on Climate Change (IPCC). IPCC predicts a maximum temperature increase for the year 2100 of from 2 to $4.5^{\circ} \mathrm{C}$, predicting equilibrium at an increase of about $3^{\circ} \mathrm{C} .{ }^{41}$

The purpose here is not to debate the accuracy of the IPCC predictions, which are part of an intense public controversy at this time, but to relate the predictions to environmental management implications in Canada's prairie provinces. What would be the effects of an increase of $3^{\circ} \mathrm{C}$ in about 100 years? Important clues can be inferred from known past climate changes, so, while climate change 
remains highly unpredictable, reasonably accurate ecozone shift scenarios are possible given input of estimated climatic conditions. Interestingly, about 6000 years ago, North America was $2-5^{\circ} \mathrm{C}$ warmer than it is now, and the grasslands ecosystem was pushed northward by about $300 \mathrm{~km} .{ }^{42}$ Hence, it is reasonable to predict that a similar shift would begin to occur in about 100 years if anthropogenic warming peaks according to the IPCC prediction.

An important implication of a warming of $3^{\circ} \mathrm{C}$ to the agricultural belt, the grassland ecozone, and the parkland ecotone in western Canada, is a likely increase in aridity. ${ }^{41,43}$ This would require a major change in usage. Such a shift in usage has already been anticipated by the Alberta Government for the South Saskatchewan River watershed, where new regulations apply as "the limit of the water resource has been nearly reached". ${ }^{44}$ The boreal forest southern boundary would move northward, substantially reducing the area of commercial forest, but the northern boundary would also shift northward, taiga moving into what is now tundra. Lakes in the boreal forest would begin to dry up as they are mostly glacial relicts and could not sustain their present levels. ${ }^{45}$ The aspen parkland ecotone would move northward as well, and could expand to engulf as much as one-half of western Canada's boreal forest. ${ }^{43}$ Urban centres in the south would have to adjust water usage, as glacial meltwater runoff from the mountains likely would end, causing very low summer flows in prairie rivers.

The scenario described above is a worst case one, so the actual environmental changes a century from now are likely to be less extensive. The nature of the ecological changes is reasonably predictable, namely northward movement of the parkland and taigatundra ecotones.

\section{Conclusions and Management Implications}

Environmental uncertainties in the prairie provinces are both naturally and anthropogenically caused. The weather is predictable only for about 5 days, ${ }^{13}$ and climate is predictable only broadly by seasons and by the long-term effects of release of greenhouse gases into the atmosphere by humans burning fossil fuels. Ecosystem boundaries, including the aspen parkland, are zones of higher natural unpredictability than are core ecosystem areas. Both natural and humancaused disturbances to ecosystems increase process unpredictability.

A conclusion derivable from the science of uncertainty in nature is that the environmental manager should not try to manage for the entire range of potential uncertainties, as this would waste energy and would be futile. Some uncertainties are useful to the manager as they help to maintain ecosystem resilience in the face of disturbances such as the predicted anthropogenically caused climate change, and these uncertainties should be identified. A danger is ever present, however, that some disturbances could tip an ecological process over its resilience threshold, initiating a chaotic interval that would result in a permanently and unpredictably altered process. Such a situation creates so high a level of uncertainty that management becomes impossible, which is not a desired condition for a manager.

The science of uncertainty applied to ecology enables the environmental manager to address some former management uncertainties and fears. These are improved selection of sites for protection, improved selection of sites for 
adaptive management, which includes site location changes over time, and research needs to determine ecological process thresholds as they apply to management areas. A new fear is the now recognized inability to accurately predict ecosystem changes that will occur after excessive human resource use in an area exceeds the threshold of the ability of the ecological processes to adapt to the changes and recover from them.

One very clear conclusion that emerges from applying uncertainty science to environmental management is that research to provide reasonably accurate estimates of disturbance thresholds of ecological processes is essential. This research needs to address both ecosystem-specific and site-specific processes over all ecozones and the ecotones in between. Once thresholds are known, it is possible to manage disturbances by setting limits and regulating human activities that cause the disturbances. Managing environmental uncertainty means managing both for maintaining some uncertainties and for limiting others, and knowing which is which. At this time we know we need to do this, but we are nowhere near having all the knowledge required to do it properly.

\section{Acknowledgements}

This paper has benefited from comments by the editors and an anonymous reviewer.

1. Horton PR (1994) Range resources in the Canadian context. In: Taha F, Abougeundia Z, Horton PR (eds) Managing Canadian rangelands for sustainability and profitability. Proceedings of the First Interprovincial Range Conference in Western Canada. Grazing and Pasture Technology Program, Regina, SK, p 16-30.

2. Fennell $J$ (2007) Water in a changing climate: understanding and adapting. In: Epp H, Ealey D (eds) Water: science, and politics. Alberta Society of Professional Biologists, Edmonton, AB, p 139.
3. Golley FB (1993) A history of the ecosystem concept in ecology. Yale University Press, New Haven, CT.

4. Simberloff D (1980) A succession of paradigms in ecology: essentialism to materialism and probabilism. Synthese 43:3-39.

5. Wilson EO (1998) Consilience: the unity of knowledge. Alfred A. Knopf, New York, NY.

6. Moyer JM (2008) Roots, branches, and seeds: exploring Western society's exploitative tendencies. Vision 9:24-34.

7. Worster D (1994) Nature's economy: a history of ecological ideas. Cambridge University Press, Cambridge.

8. Odum EP (1959) Fundamentals of ecology. W.B. Saunders Company, Philadelphia, PA.

9. Tansely AG (1935) The use and abuse of vegetational concepts and terms. Ecology 16:284307 .

10. Higashi M, Burns TP (1991) Theoretical studies of ecosystems: a network perspective. Cambridge University Press, Cambridge.

11. Harvey D (1969) Explanation in geography. Edward Arnold, London.

12. Hawking SW (1988) A brief history of time. Bantam Books, New York, NY.

13. Lorenz EN (1964) Deterministic periodic flow. Journal of Atmospheric Science 20:282-293.

14. Yorke J, Li TY (1975) Period three implies chaos. American Mathematical Monthly 82:985-992.

15. Horgan J (1996) The end of science. Broadway Books, New York, NY.

16. Shalizi C (2010) The bootstrap. American Scientist 58:186-190.

17. Schneider ED, Kay JJ (1994) Complexity and thermodynamics: towards a new ecology. Futures 26:626-647.

18. Epp HT (1997) Protecting ecological processes. Blue Jay 55:247-253.

19. Rickleffs RE, Naveh Z, Turner RE (1984) Conservation of ecological processes. Environment $8(2): 6-16$. 
20. Fryxell JM, Greever J, Sinclair ARE (1988) Why are migratory ungulates so abundant? American Naturalist 131:781-798.

21. Crete M, Huot J (1993) Regulation of a large herd of migratory caribou: summer nutrition affects calf growth and body reserve of dams. Canadian Journal of Zoology 71: 2291-2296.

22. Epp H, Dyck I (2002) Early human-bison population interdependence in the Plains ecosystem. Great Plains Research 12:323-337.

23. Kelsall JP (1968) The caribou. Canadian Wildlife Service, Ottawa, ON.

24. Wilson EO (ed) (1988) Biodiversity. National Academy Press, Washington, DC.

25. Wilson EO (1999) The diversity of life. WW Norton \& Co., New York, NY.

26. Holling CS (1973) Resilience and stability of ecological systems. Annual Review of Ecology and Systematics 4:1-24.

27. Pfisterer A, Schmid B (2002) Diversity-dependent production can decrease the stability of ecosystem functioning. Nature 416:84-86.

28. Johnson LB, Host GE (2010) Recent developments in landscape approaches for the study of aquatic ecosystems. Journal of the North American Benthological Society 29:41-66.

29. Reice $S$ (1994) Nonequilibrium determinants of biological community structure. American Scientist 82:424-435.

30. Kay JJ (1991) A nonequilibrium thermodynamic framework for discussing ecosystem integrity. Environmental Management 15:483-495.

31. Altieri MA (2000) Modern agriculture: ecological impacts and the possibilities of truly sustainable farming. Division of Insect Biology, University of California, Berkeley. Available at: <http://www.cnr. berkeley.edu/ agroeco3/modern__agriculture.html >

32. Strayer DL, Dudgeon D (2010) Freshwater biodiversity conservation: recent progress and future challenges. Journal of the North American Benthological Society 29:344-358.

33. Shugart HH (1998) Terrestrial ecosystems in changing environments. Cambridge University Press, Cambridge.
34. Simberloff D (1994) The ecology of extinction. Acta Palaeontologica Polonica 38:159-194.

35. Bird RD (1961) Ecology of the aspen parkland in western Canada. Contribution No. 27, Research Station, Canada Agriculture, Winnipeg, MB

36. Secoy D (2005) Ecozones and ecoregions. In: The encyclopedia of Saskatchewan. Canadian Plains Research Center, Regina, SK, p 270-273

37. Walker BH, Norton GA (1982) Applied ecology: towards a positive approach. II. Applied ecological analysis. Journal of Environmental Management 14:325-342.

38. Holling CS (ed) (1978) Adaptive environmental assessment and management. John Wiley \& Sons, New York, NY.

39. Brand P (1993) Regional landscape planning for sustainable agriculture. In: Marczyk JS, Johnson DB (eds) Sustainable landscapes. Proceedings of the Third Symposium of the Canadian Society for Landscape Ecology and Management, University of Alberta, Edmonton, June 1992, p 27-35.

40. Epp HT (1995) Application of science to environmental impact assessment in boreal forest management: the Saskatchewan example. Water, Air and Soil Pollution 82:179-188.

41. Intergovernmental Panel on Climate Change (IPCC) (2010) Summaries for policymakers. IPCC, Geneva.

42. Vance RE, Beaudoin AB, Luckman BH (1994) The paleoecological record of $6 \mathrm{ka}$ BP climate in the Canadian prairie provinces. Geographie Physique et Quaternaire 49:81-98.

43. Hogg EH, Hurdle PA (1995) The aspen parkland in western Canada: a dry-climate analogue for the future boreal forest. Water, Air and Soil Pollution 82:391-400.

44. Ohrn D (2007) Progress toward a water management plan for the South Saskatchewan River Basin in Alberta, Canada. In: Epp H, Ealey D (eds) Water: science and politics. Alberta Society of Professional Biologists, Edmonton, AB, p 7-19.

45. Epp H, Ealey D (2007) Canada, the bluest country: introductory remarks. In: Epp H, Ealey D (eds) Water: science and politics. Alberta Society of Professional Biologists, Edmonton, AB, p 3-4. 